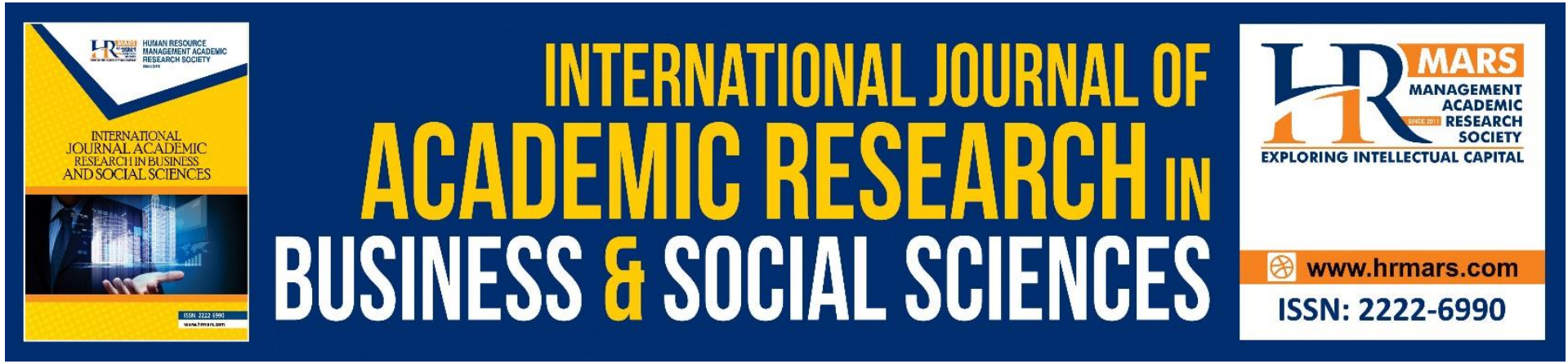

\title{
The Archers' Attitude towards Sport Psychology Consultation
}

Mon Redee Sut Txi, Hairul Anuar Hashim, Oleksandr Krasilshchikov and Fatin Nurfatehah Mat Salleh

To Link this Article: http://dx.doi.org/10.6007/IJARBSS/v11-i7/10325

DOI:10.6007/IJARBSS/v11-i7/10325

Received: 20 May 2021, Revised: 23 June 2021, Accepted: 04 July 2021

Published Online: 27 July 2021

In-Text Citation: (Txi et al., 2021)

To Cite this Article: Txi, M. R. S., Hashim, H. A., Krasilshchikov, O., \& Salleh, F. N. M. (2021). The Archers' Attitude towards Sport Psychology Consultation. International Journal of Academic Research in Business and Social Sciences, 11(7), 916-923.

Copyright: (c) 2021 The Author(s)

Published by Human Resource Management Academic Research Society (www.hrmars.com)

This article is published under the Creative Commons Attribution (CC BY 4.0) license. Anyone may reproduce, distribute, translate and create derivative works of this article (for both commercial and non-commercial purposes), subject to full attribution to the original publication and authors. The full terms of this license may be seen

at: http://creativecommons.org/licences/by/4.0/legalcode

Vol. 11, No. 7, 2021, Pg. 916 - 923

Full Terms \& Conditions of access and use can be found at http://hrmars.com/index.php/pages/detail/publication-ethics 


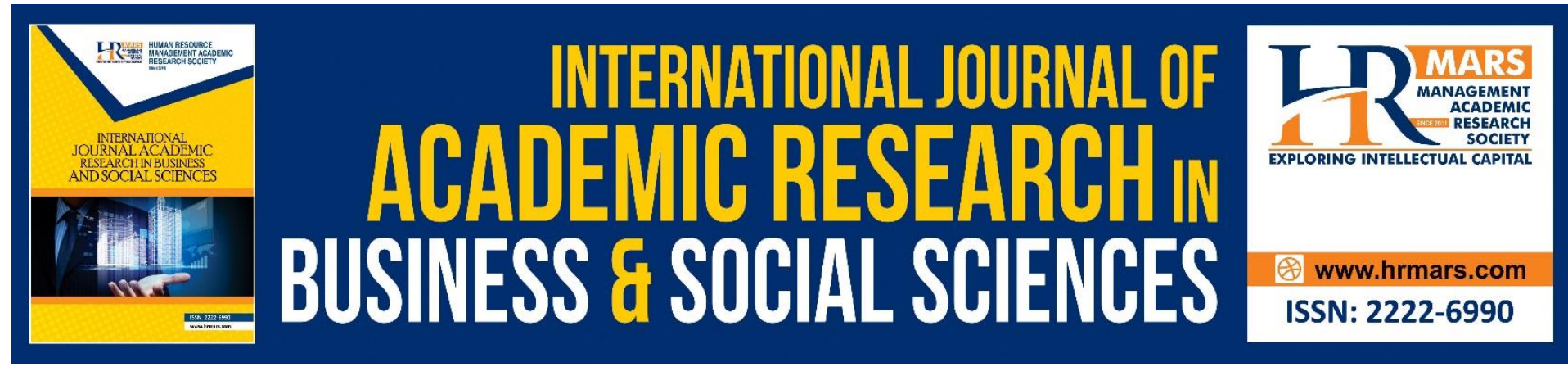

\title{
The Archers' Attitude towards Sport Psychology Consultation
}

\author{
Mon Redee Sut Txi ${ }^{1}$, Hairul Anuar Hashim², Oleksandr \\ Krasilshchikov ${ }^{2}$ and Fatin Nurfatehah Mat Salleh ${ }^{1}$ \\ ${ }^{1}$ Faculty of Sport Sciences and Coaching, Universiti Pendidikan Sultan Idris, \\ 35900 Tanjung Malim, Perak, Malaysia, ${ }^{2}$ School of Health Sciences, Universiti Sains Malaysia, \\ 16150 Kubang Kerian, Kelantan, Malaysia
}

\begin{abstract}
The purpose of this study was to examine the effects of archer' attitude towards sport psychology on the effectiveness of the intervention. The study involved 21 junior archers (age $=15.0 \pm 1.7$ years) from recurve and compound division of State's level team. The archers were divided into three groups including psychological $(P)$, psychological with physical fitness $(\mathrm{P}+\mathrm{PF})$ and control groups (CON). They were followed a 12-week intervention training program. Sport Psychology Attitudes-Revised SPA-R (Martin et al., 2002) was used to measure the level of attitude among the both experimental group (P) and (P+PF). The outcome variables were measured after the $12^{\text {th }}$ week of the intervention. The athletes in this study reported a high score of confidence in sport psychology, which indicated that they have a positive attitude toward the sport psychology services $(M=5.27, S D=0.69)$. In term of gender, the results showed most of the female athletes have more positive attitude towards sport psychology services which exhibit better outcomes in all of the measured parameters except for the personal openness. It shown that attitudes may moderate the effectiveness of training program provided to the athletes if it is not given attention by psychologists.
\end{abstract}

Keywords: Archer's Attitude, Sport Psychology Consultation, State's Level Athletes

\section{Introduction}

It is widely acknowledged that mental skill training may benefit athletes especially in high performance sport (Murphy \& Tammen, 1998). The benefits of mental skill training are not limited to performance enhancement, but also for general well-being, improving psychological skill and personal development of athletes (Anderson, 1999; Danish, 1992; Harmison, 2000). Despite the potential benefits of psychological training, it has been shown in sport psychology literature that some athletes and coaches remain hesitant to use these services (Martin, 1998). The reasons for not taking the advantage of sport psychology services reported in the past studies include the belief that it is not important for their performance, lack of awareness of its potential benefits, (Leffingwell, 2001), fear of stigma associated with seeing mental health professional (Ravizza, 1988; Zakrajsek et al., 2007), and the belief that only weak and vulnerable athletes used psychology trainings (Weinberg \& Williams, 2001). 
In order to encourage athletes seeking out sport psychology services voluntarily and adhere to psychological training program; their attitude, motivation, beliefs and behavior towards the services must be addressed (Bull, 1991). This is a crucial because their views will have implications for acceptability, adoption, and service use (Brewer, Jeffers, Petitpas, \& Van Raalte, 1994). Various instruments have been used to assess the level of attitudes among athletes and expectations about sports psychology. One of a widely used instrument is the Sport Psychology Attitude - Revised SPA-R; Martin et al., 2002). It comprises of four constructs; stigma tolerance (i.e., the belief that athletes are negatively labeled if they seek help from consultants), confidence in sports psychology consultation (i.e., the belief that consultation and mental training are useful), personal openness (i.e., willingness to try out consultation and mental training), and cultural preference (i.e., the identification with its own cultural background and preference for working with consultants with the similar background). The SPA - $R$ has been shown to have strong psychometric properties and have been used in multi countries.

In Malaysia sport setting, research on this issue is limited. One study involving young state level athletes reported that they have positive views towards sport psychology services, and were not likely to be resistant to sport psychology services. They also reported high levels of confidence in sport psychology, which indicated that they believed that sport psychology consultation and mental training might be useful and beneficial. Moreover, gender did not significantly influence athletes' attitude towards seeking sport psychology assistance (Maimunah \& Hashim, 2013).

\section{Methodology}

\section{Participants}

The sample comprised of fourteen junior archers (mean age: $15.21 \pm 1.67$ years old). They consisted of 11 boys and 10 girls. The age of the participants was between 13 to 18 years old. There were recurve and compound division of State's level who were preparing for Sukan Malaysia (SUKMA). Signed Informed consent form was also obtained from all participants and their parents or legal guardians. Approval by the Ethics Committee of Universiti Sains Malaysia was obtained prior to the start of this study.

\section{Measurement Instrument}

\section{A) Sport Psychology Attitudes-Revised (SPA - R; Martin et al., 2002)}

Sport Psychology Attitudes-Revised (SPA - R; Martin et al., 2002) was used to assess the level of attitude toward training outcomes. SPA-R (2002) consists of four subscales with 7 items pertaining to stigma tolerance, 8 items on confidence in consultant, 6 items on personal openness and 4 more items on cultural preference. The 25 items were linked to a 7-point Likert scale ranging from 1 (strongly disagree) to 7 (strongly agree). Each subscale is exemplified by the following: stigma tolerance - I would not go to a sports psychology consultant because my teammates would harass me, confidence in a consultant - A sports psychology consultant can help athletes improve their mental toughness, personal openness - There is a certain problem, which should not be discussed outside one's immediate family, and cultural preference - I respect the opinions of people of my own culture more so than those of people of another culture. 
The adapted version used by Sharifah and Hashim (2013) was used in this study. The Bahasa Malaysia translated version has shown adequate findings in term of its internal consistency. Specifically, it exhibits alpha coefficients of 0.83 for the 7 -item Stigma Tolerance, $a=.84$ for the 8-item Confidence in Sports Psychology, 0.64 for the 6-item Personal Openness, and 0.66 for the 4-item Cultural Preference subscale.

Sport Psychology Attitudes-Revised SPA-R (Martin et al., 2002) was used to measure the level of attitude among the both experimental group $(\mathrm{P})$ and $(\mathrm{P}+\mathrm{PF})$. The outcome variables were measured after the $12^{\text {th }}$ week of the intervention.

\section{Intervention}

After three different groups were matched, both experimental groups followed a researcher's 12-week intervention training program, while the control group was following its normal routine coaching program. All groups were trained six days a week, Monday to Saturday and had a rest day on Sunday. Each group was trained under the supervision of qualified coaches and also with Sport and Conditioning Instructor, which have officially qualified in this area (at least Level 1 Sport Specific Certificate in Archery and Level 1 Sport Specific Certificate issued by the National Sport Council). They were closely monitoring this training programme for a period of 12 weeks. The description of training and procedure were as follows:

i. Experimental group one

For experimental group one $(\mathrm{P})$, participants followed the psychological training provided by researcher throughout the 12 weeks of intervention.

\section{ii. Experimental group two}

For experimental group two $(P+P F)$, the participants followed the psychological training as an experimental group one and physical training program provided by the researcher for 12 weeks of intervention.

iii. Control group

There are no intervention programs were received from the researcher for participants in the control group (CON). However, they followed the normal routine training programme prepared by their coach for 12 weeks. Training intensity, volume, and frequency are similar, in order to make sure that during the intervention programme, all groups received the same intensity, volume and frequency.

\section{Data Analysis}

All statistical analyses were performed using the Statistical Package for Social Sciences (SPSS version 22). Descriptive statistic (mean, standard deviation, frequency and average) was used to screen and data analysis. All values are expressed as mean \pm SD. 


\section{Result}

Table 1: $\quad$ Characteristics of participants

The demographic characteristics data are reported as mean \pm SD for the age, height $(\mathrm{cm})$, weight $(\mathrm{kg})$, years of experience and totals of training hours in one week for both experimental groups are shown in Table 1.

\begin{tabular}{|c|c|c|c|c|c|}
\hline Variables & $\mathbf{N}$ & Minimum & Maximum & Mean & Std. Deviation \\
\hline Age & 14 & 13 & 17 & 15.21 & 1.67 \\
\hline Height & 14 & 148 & 172 & 159.75 & 7.74 \\
\hline Weight & & 40.2 & 90.0 & 60.64 & 13.70 \\
\hline Years of experience & 14 & 2 & 7 & 4.14 & 1.35 \\
\hline \multicolumn{6}{|c|}{ Total of training hours } \\
\hline in one week & 14 & 23 & 24 & 23.79 & 0.43 \\
\hline
\end{tabular}

Table 2: $\quad$ Archer's attitude towards sport psychology consultation

\begin{tabular}{llllll}
\hline \multicolumn{1}{c}{ Subscale } & $\mathbf{N}$ & Minimum & Maximum & Mean & Std. \\
\hline $\begin{array}{l}\text { Deviation } \\
\begin{array}{l}\text { Stigma Tolerance } \\
\quad 0.92\end{array}\end{array}$ & 14 & 1.00 & 4.11 & 2.17 & \\
$\begin{array}{l}\text { Confidence of sport psychology } \\
\quad 0.69\end{array}$ & 14 & 3.66 & 6.13 & 5.27 \\
$\begin{array}{l}\text { Personal openness } \\
\quad 0.84\end{array}$ & 14 & 2.92 & 5.75 & 4.65 \\
$\begin{array}{l}\text { Cultural Reference } \\
\quad 1.25\end{array}$ & 14 & 1.31 & 5.25 & 2.69
\end{tabular}

According to the descriptive data for Sport Psychology Attitude-Revised (SPA-R) questionnaire in table 2 indicates that confidence in sport psychology consulting ( $M=5.27, S D=0.69)$ was a highest score represents the positive attitude among archers. Followed by personal openness with a moderately high score $(M=4.65, S D=0.84)$. The cultural reference $(M=2.96, S D=1.25)$ and stigma tolerance $(M=2.17, S D=0.92)$ subscale are the lowest score, which indicates that they willing to go to a sport psychology, when necessary, without thinking about teammates perception and they also can work with a sport psychology with different cultures background. 
Table 3 illustrates the score of female and male archers for each subscale. According to the

Table 3: Mean and standard deviation by gender

\begin{tabular}{|c|c|c|c|c|c|c|c|c|c|}
\hline & & \multirow[t]{2}{*}{$\mathrm{N}$} & \multirow[t]{2}{*}{ Mean } & \multirow[t]{2}{*}{$\begin{array}{c}\text { Std. } \\
\text { Deviation }\end{array}$} & \multirow[t]{2}{*}{$\begin{array}{l}\text { Std. } \\
\text { Error }\end{array}$} & \multicolumn{2}{|c|}{$\begin{array}{l}\text { 95\% Confidence } \\
\text { Interval for Mean }\end{array}$} & \multirow[t]{2}{*}{$\begin{array}{c}\text { Minimu } \\
\mathrm{m}\end{array}$} & \multirow[t]{2}{*}{$\begin{array}{c}\text { Maxim } \\
\text { um }\end{array}$} \\
\hline & & & & & & $\begin{array}{l}\text { Lower } \\
\text { Bound }\end{array}$ & $\begin{array}{l}\text { Upper } \\
\text { Bound }\end{array}$ & & \\
\hline \multirow{3}{*}{$\begin{array}{l}\text { Stigma } \\
\text { Tolerance }\end{array}$} & Female & 7 & 2.2041 & 1.09841 & .41516 & 1.1882 & 3.2199 & 1.00 & 4.11 \\
\hline & Male & 7 & 2.1429 & .80205 & 30315 & 1.4011 & 2.8846 & 1.00 & 3.36 \\
\hline & Total & 14 & 2.1735 & .92453 & 24709 & 1.6397 & 2.7073 & 1.00 & 4.11 \\
\hline \multirow{3}{*}{$\begin{array}{l}\text { Confident } \\
\text { to SP }\end{array}$} & Female & 7 & 5.4196 & .83947 & 31729 & 4.6433 & 6.1960 & 3.66 & 6.13 \\
\hline & Male & 7 & 5.1205 & .51804 & .19580 & 4.6414 & 5.5996 & 4.19 & 5.66 \\
\hline & Total & 14 & 5.2701 & .68789 & .18385 & 4.8729 & 5.6673 & 3.66 & 6.13 \\
\hline \multirow{4}{*}{$\begin{array}{l}\text { Personal } \\
\text { openness }\end{array}$} & Female & 7 & 4.3690 & .97493 & .36849 & 3.4674 & 5.2707 & 2.92 & 5.71 \\
\hline & Male & 7 & 4.9405 & .62493 & .23620 & 4.3625 & 5.5184 & 3.83 & 5.75 \\
\hline & Total & 14 & 4.6548 & .84074 & .22470 & 4.1693 & 5.1402 & 2.92 & 5.75 \\
\hline & Female & 7 & 2.7768 & 1.19616 & .45211 & 1.6705 & 3.8831 & 1.50 & 4.19 \\
\hline \multirow{2}{*}{$\begin{array}{l}\text { Cultural } \\
\text { preference }\end{array}$} & Male & 7 & 2.5804 & 1.38336 & .52286 & 1.3010 & 3.8598 & 1.31 & 5.25 \\
\hline & Total & 14 & 2.6786 & 1.24660 & .33317 & 1.9588 & 3.3983 & 1.31 & 5.25 \\
\hline
\end{tabular}

Mean and Standard Deviation score showed that the most of the female archers were perceived positive attitude toward sport psychology consulting in most of the subscale except for the personal openness.

\section{Conclusion}

During the competition, athletes must face normal, excitement, and dynamic situations. Various factors such as gender, race, ethnicity, social class, and age can influence sports participation and the attitudes and perceptions of those involved. Therefore, some athletes and coaches may be hesitant to seek professional help (Zakrajsek et al., 2011). Understanding the attitudes of potential sports participants toward sports psychology and the use of services can help trained consultants determine the strategies and mental skills that might attract to different groups and identify several ways to establish early relationships.

The findings of a study using SPA-R (Martin et al., 2002) showed that stigma tolerance, confidence to sport psychology, personal openness and cultural preference level can influence the attitudes of athletes towards sport psychology consultation. In this study found that archers have confident and belief in sport psychology consultation throughout the intervention program. This is consistent with the most studies found that people have a positive image of psychologists (Cordella et al., 2016; Wood, Jones, \& Benjamin, 1986). Confidence in sports psychology consultation refers to an athlete's scepticism about or reliance on the usefulness of sports psychology.

However, we observe more female archers perceived positive attitude toward sport psychology consulting in most of the subscale except for the personal openness. Personal openness refers to an individual's willingness and ability to discuss problems and issues with others (Anderson et al., 2004). This is an important trait, as a reluctance to share personal information can be a barrier to use sports psychology (Donohue et al., 2004). They may 
assume that there is a certain problem, which should not be discussed outside one's immediate family or unfamiliar individuals.

Therefore, by learning the perceptions and attitudes of both genders who regularly participate in athletics toward sports psychology could help sports practitioners target and promote positive attitudes to seeking psychological assistance. By developing a better understanding of athletes ' perceptions and attitudes could also promote strategies to reduce the stereotypical and myth-laden view of counseling and consulting in sports psychology (Esters et al., 1998; Martin et al., 2002).

Besides that, this finding was in agreement with the study conducted by Martin (2005) which indicated that the type of sport in which athletes have been socialized and through can also play a role in whether assistance is sought from a consultant in sports psychology. His results showed that athletes competing in physical contact sports could have a more negative view of consulting sports psychology than participants in physical non - contact sports. The archer is a non-contact sport and mostly, they willing to seek help from sports psychology. In addition, athletes who played physical contact sports found sports psychology to be more stigmatizing than athletes who were not in contact sports. Athletes who participate in physical contact sports tend to accept the pain associated and are generally unwilling to seek help compared to non - contact sports (Martin, 2005; Vogel, Wade, and Hackler, 2007).

Similarly, these were also showed that to influence their subsequent attitudes towards consulting in sports psychology is by the athletes with past psychological experience. (Anderson et al., 2004; Martin, 2005; Martin et al., 2004). Athletes exposed to psychological services in sport are more willing to work with consultants, more confident in the mental skills training and less likely to stigmatize services than athletes without prior experience in consultation (Wrisberg et al., 2009). However, the quality of past consultation experience also seems to be a critical factor affecting athletes' interest in sport psychological activities (Wrisberg et al., 2009). That is, athletes that have positive experiences are preferred to continue to use services compare with athletes who have negative ones. Apart from that, since the archery is a fine skill sport, psychological consultation plays a crucial role as a part of a training program related to psychological elements. Hence, the positive attitude is important and need to pay more intention by the psychological consultant because it may help an athlete throughout the preparation process in achieving their gold.

\section{References}

Anderson, A. G., Hodge, K. P., Lavallee, D., \& Martin, S. (2004). New Zealand athletes' attitudes towards seeking sport psychology consultation. New Zealand Journal of Psychology, 33, 129-136.

Anderson, J. R. (2004). Cognitive psychology and its implications (6th ed.). Worth Publishers. p. 519. ISBN 978-0-7167-0110-1.

Bull, S. J. (1991). Personal and situational influences on adherence to mental skills training. The Sport Psychologist, 13, 121-132.

Cordella, B., Greco, F., Di Tirani, M., Renzi, A., La Corte, C., \& Solano, L. (2016). The impact of joint consultation with family physicians on perception of psychologists. Professional Psychology, Research and Practice, 47(2), 102-109. 
Donohue, B., Dickens, Y., Lancer, K., Covassin, T., Hash, A., Miller, A., \& Genet, J. (2004). Improving athletes' perspectives of sport psychology consultation: A controlled evaluation of two interview methods. Behavior Modification, 28, 182-193.

Esters, I. G., Cooker, P. G., \& Ittenbach, R. F. (1998). Effects of a unit of instruction in mental health on rural adolescents' conceptions of mental illness and attitudes about seeking help. Adolescence, 33, 469-476.

Fischer, E. H., \& Turner, J. L. (1970). Orientations to seeking professional help: Development and research utility of an attitude scale. Journal of Consulting and Clinical Psychology, 35, 79-90. DOI: 10.1037/h0029636.

Léger, L. A., Lambert, J. A. (1982). Maximal multistage 20-m shuttle run test to predict $\backslash$ dot $\mathrm{VO}_{2}$ max. Europe Journal Apply Physiology, 49 (1):1-12.

Martin, S. B. (2005). High school and college athletes' attitudes toward sport psychology consulting. Journal of Applied Sport Psychology, 17, 127-139. doi:10.1080/10413200590932434.

Martin, S. B., Kellmann, M., Lavallee, D., \& Page, S. J. (2002). Development and psychometric evaluation of the sport psychology attitudes--Revised form: A multiple group investigation. The Sport Psychologist, 16, 272-290.doi:10.1123/tsp.16.3.272.

Martin, S. B., Lavallee, D., Kellmann, M., \& Page, S. J. (2004). Attitudes toward sport psychology consulting of adult athletes from the United States, United Kingdom, and Germany. International Journal of Sport and Exercise Psychology, 2, 146160.doi:10.1080/1612197X.2004.9671738.

Saha S., Mukhopadhyay, P., Chattopadhyay, P. K., Biswas, D., \& Saha, S. (2005a). Arousal modulation as predictor of achievement motivation in high soccer performers. Reading in Sports Psychology. Jitendra Mohon and Meena Sehgal (Eds.) Friends Publications, India, 116-146.

Schell, J., and Leelarthaepin, B. (1994). Physical Fitness Assessment in Exercise and Sports Science. 2nd Ed, Leelar Biomedisience Services, Matraville, NSW. p. 327.

Vogel, D. L., Wade, N. G., \& Hackler, A. H. (2007). Perceived public stigma and the willingness to seek counseling: The mediating roles of self-stigma and attitudes toward counseling. Journal of Counseling Psychology, 54, 40-50. DOI:10.1037/00220167.54.1.40.

Wood, W., Jones, M., \& Benjamin, L. T. (1986). Surveying psychology's public image. American Psychologist, 41(9), 947-953.

Wrisberg, C. A., \& Martin, S. B. (1994, October). Attitudes of African-American and Caucasian athletes towards sport psychology consultants. Paper presented at the meeting of the Association for the Advancement of Applied Sport Psychology, Incline Village, NV.

Wrisberg, C. A., Simpson, D., Loberg, L. A., Withycombe, J. L., \& Reed, A. (2009). NCAA Division-I student-athletes' receptivity to mental skills training by sport psychology consultants. The Sport Psychologist, 23, 470-486. doi:10.1123/tsp.23.4.470.

Zakrajsek, R. A., Martin, S. B., and Zizzi, S. J. (2011). American high school football coaches 'attitudes toward sport psychology consultation and intentions to use sport psychology services. International Journal of Sport Science and Coaching, 6, 461-478. DOI: 10.1260/1747-9541.6.3.461. 